\title{
Conceptually Examine Subliminal Perception in Marketing and Strategy Terms
}

\author{
K.Prabhakar Rajkumar, M.Priya
}

\begin{abstract}
Subliminal audio perception, additionally known as subliminal audio information. are actually information, either graphic or even acoustic, that are presented merely beyond the limit of human understanding. A subliminal audio viewpoint might certainly not be actually distinct good enough that the aware mind may enroll it however be actually discernible good enough for the subconsciousness mind. The very same applies to a subliminal audio graphic. The utmost measure of just how effective a company's marketing technique is exactly how effectively the information provided through industrying embed the minds of buyers as well as influences them to purchase the product or services of the organisation. As opposed to preferred technique, marketing technique is not taken out of lean sky. At least it should not be actually. A marketing strategy should outgrow the business's market value proposition. The worth proposal often provides the crucial notification for all advertising and marketing One strategy that marketers are generally thinking about is subliminal audio understanding. This causing is subliminal audio perception. The resulting kind of advertising and marketing is known as subliminal audio advertising and marketing.
\end{abstract}

Keywords : Subliminal, perception, consumers, conscious, organisation, marketing, strategy.

\section{INTRODUCTION}

The condition subliminal audio is stemmed from the conditions sub (listed below) and limen (threshold), and also it describes impression so refined it can easily certainly not reach aware understanding. Many of the study on subliminal audio impression is carried out on graphic subliminal audio viewpoint. For instance, one may flash words or even photos thus promptly on a computer system display (generally faster than 10-15 milliseconds) that beholders possess the feeling they carry out not find anything at all. To put it simply, they are not consciously aware of the here and now expressions or even photos. Nevertheless, such graphic stimulations are refined unconsciously, as well as they can possess quick as well as subtle results on our emotion and thinking. On top of that, some research study has been actually done on auditory subliminal audio understanding. No dependable scientific documentation exists, nevertheless, for mental effects of auditory subliminal audio assumption.

\section{SUBLIMINAL MESSAGES}

The subliminal point is actually regulated due to the suggestion that the mindful thoughts judges as well as the subconsciousness one shows the memory database. One of the

Revised Manuscript Received on November 05, 2019.

Dr. K.Prabhakar Rajkumar, Associate Professor, Department of Commerce, Periyar University, Salem -11, Tamil Nadu, India.

M.Priya, PH.D Research Scholar, Periyar University, Salem -11, Tamil Nadu, India.Email : kudalkprk6@yahoo.co.in. most well-known example was actually the Snacks Experiment, when a North United States cinema inserted popcorn photos, within the flick frames, that it was actually predicting. With this activity they had the capacity to prove that unconsciously individuals regarded the wish to consume snacks.

All movies give some subliminal visual stimulus. The information got at the center of the monitor is gotten by the aware thoughts, as well as a thinking is actually given off on all of them prior to holding all of them. The details that comes from the edges of the display screen, prevents the conscious mind and goes straight to the subconscious one without being evaluated, which produces a much deeper sensation concerning it. Therefore it is that when one looks at a flick on a large display it is actually so much more touching, even more moving. The same film, found on television, does certainly not commonly create so much of an impact. This is because on the small screen all the info is actually acquired due to the mindful mind, and also it is evaluated before being stored in the subconscious.

The auditory subliminal audio information function in similarly. When one gets details that goes into the subconsciousness directly, this is not evaluated, it is merely kept and one behaves based on it.

The troubles perform certainly not make on their own with the memory yet with the possibility of stiring up. This implies that so that others remember what they have listened to, one need to take care with the method which the relevant information is presented.

Behavior carries out not relies only of the mindful reactions, through which one had "opportunity to believe", however instead there are actually 0.5 seconds through which one can react, depending on to what our non aware mind purchases or (in various other conditions) decides, and which enthusiasms teaching therefore in order to control those acts, it is actually that aspect of the brain certainly not remembered, where systems take action below the aware one. This is the foundation of what is actually known as subliminal audio viewpoint.

\section{Subliminal Audio Effect:}

Subliminal influence and also subliminal texting are actually terms utilized to illustrate when information are actually masked behind-the-scenes of sound (i.e. music, radio broadcasts, industrial jingles, and so on) and/or photos in chances of embedding certain information in your subconscious notions. While the principle of subliminal effect 
is a questioned issue, the following supplies an overview of the principle generally. There is a lot dispute regarding whether it operates and whether it doesn't operate.

The quite magical or even magical concept of subliminal influence signs back to historical opportunities when individuals attempted to control other individuals's thoughts. It was believed that you could possibly regulate somebody else's thoughts if you hid messages in history sound. That control was actually sought to acquire power over the opponent, maneuver individuals in to carrying out things they would not commonly carry out, or maybe help somebody capture of his personal condition. Subliminal audio effect can additionally produce beneficial outcomes such as helping an individual burn fat, promoting a person to stop cigarette smoking, or helping people strengthen their thought and feelings concerning on their own, such as self-image or self-worth.

\section{Viewpoint:}

The identified world is typically a mirror of the preconceived individual concepts as well as of the worries. Taking a minor instance, that of the spit, if one collects some spit in the mouth, one experiences how the tongue is being actually oiled as it moves toward the teeth, giving a non distressing feeling. At that point one takes a tidy glass, spits inside it and also drinks it. One regards that this action of taking in one thing that until a minute earlier was pleasing, ends up being revolting. The issue is that assumption and also perspective towards the exact same trait, improvement considerably. What was something well-maintained and all-natural has ended up being, in that action outside the body system, something filthy and also uncomfortable. It is actually certainly not the spit that has changed, it is actually just the analysis made from it. The development of a large sensibility is actually a specific objective that enables interaction capacity and also all at once the rational one, which significantly rebounds in the understanding of the atmosphere and in its very own evolution.

Alternatively the person possesses a series of constraints that restrict, and also distort, the atmosphere details. This gives consequently a certain dealing with, to the impression which one possesses of it. In this feeling it is where emotional states relate to viewpoint, the recognized enrollment is actually filtered by the mental valuation. "Emotions (thirteen ), are those which in reality determine what our experts perform, although we believe that our team determine it logically, factor simply interferes in the how our experts do it, that is actually to claim in the operation". From a publicity viewpoint, you may develop an emotional propensity in the direction of an usage, offering differential worths to items that did not possess a certain area, that is actually exactly how our team note that trade scores are actually located and also are actually removed through others

\section{Perception Methods:}

There is no other way of developing exact expression restrictions, however each product consumption situation, undergoes various stages, therefore in the eatable products, our team discover prep work, presentation, consumption and blog post - intake, where every one of those phases need to be easily sent, to ensure the individual is convinced. Often times the modifications take place, certainly not just because of the feeling of the viewed phrases, yet due to the fact that the profession market takes charge to retransmit the scenarios through its very own specialists. Specifically it is actually monitored that in consumption choices there is actually a retrade markable possibility of customers' method per other. In an empire where interactions are actually so fast as well as crossed, the marketer's mind may not be actually segregated as well as could be determined knowingly or even instinctively, by situation( 15 ). Neurology and psychological science studies have actually strongly assisted the final thought that the detects (consisting of those that have actually certainly not yet been actually found) run in at the very least two viewpoint levels. The info is actually compiled in what could be named cognitive or conscious amount, in which each individual being realizes consciously what is actually occurring. Also concurrent as well as constant info is gathered at a subliminal audio level, level seemingly certainly not conscious of the data that reach out to the brain.

\section{What Is Actually Advertising Method?}

An advertising approach describes an organisation' overall tactical plan for connecting with possible customers and also switching all of them in to consumers of the services or products your business delivers. A marketing strategy contains the provider's market value proposal, vital brand texting, data right on the button customer demographics, and various other high-level aspects.

\section{Marketing Strategy vs. Advertising Plan}

The advertising technique notifies the marketing plan, which is actually a document that information the particular types of advertising and marketing activities a provider performs and also contains timetables for rolling out various marketing initiatives.

Advertising techniques need to ideally have longer life-spans than personal advertising and marketing programs since they include value suggestions and also other crucials of a firm's brand, which normally accommodate constant over the long run. In short, advertising tactics deal with big-picture texting, while advertising plans delineate the logistical particulars of details projects.

Scholars continue to dispute the accurate definition of advertising and marketing approach, for that reason various definitions exist. The adhering to quotes aid take shape the distinctions of (present day) advertising tactic:

" The single reason of advertising and marketing is actually to market additional to more individuals, often as well as at higher rates." (Sergio Zyman, advertising manager as well as former Coca-Cola and also JC Penney marketing expert).

" Advertising and marketing is actually no longer concerning the stuff that you make, yet regarding the tales you tell." (Seth Godin, former company executive and business owner).

" The intention of marketing is to recognize and know the consumer thus well the product or service accommodates him as well as sells on its own." (Peter Drucker, accepted as founding modern-day administration).

" Marketing's work is never ever done. It has to do with permanent activity. We have to remain to introduce every day."

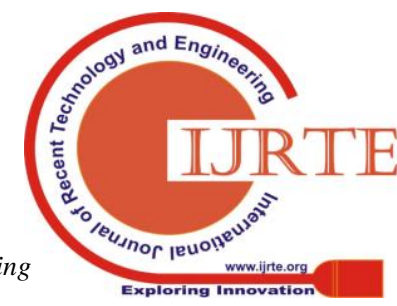


(past vice office chair and chief marketing police officer, GE).

" Take two ideas and placed them with each other to make one new idea. Besides, what is actually a Snuggie however the mutation of a blanket and also a robe?" (Jim Kukral, speaker and also writer of "Interest!").

\section{The Development of Marketing Approach.}

A carefully-cultivated marketing strategy need to be essentially originated in a company's value proposition, which recaps the competitive advantage a company holds over rivalrous organisations. As an example, Walmart is actually widely called a markdown retailer with "everyday affordable price," whose business procedures and advertising and marketing efforts focus on that suggestion.

Whether it's a printing ad concept, mass customization, or even a social media sites project, an advertising and marketing asset could be evaluated based on how properly it corresponds a company's center worth suggestion. Market research can be valuable in laying out the efficacy of a given campaign as well as can easily aid identify low compertition target markets, in order to accomplish necessary goals and also boost sales.

\section{LITERATURE REVIEW}

His research explores the responsibility of mindful As well as also subconsciousness believed when it includes choose, showing that with each one of the 5 practices, subconscious assortment Creating resulted in better options than aware one.

Presume Different: The Advantages of Subconsciousness Thought And Feelings As Well As Sensations in Preference Development and Choice Creating. Log of Individual as well as also Social Psychological Science, 87 (55 Cronley, Kardes, \& Hawkins, 2006 As agent of marketing states increases, Hence performs the viewed credibility of the Information. They ultimately suggest that mindful and also subconscious ideas operate in various techniques.

Impacts on the Illusory Truth Lead To Consumer Viewpoint. Developments in Buyer Examination, Till 4 direct exposures to an advertising campaign of an Unfamiliar brand there is in fact no logical variant In relation to its efficiency. Coming from 5 direct exposures it Begins to be prosperous. Moreover, advertising campaigns For familiar trademark name typically damage rapidly, While those for uncommon ones need various Presences to utilize in. Ad Ads Along With a New Lense. Publication of Marketing Study (July-August, 2001) Tellis, 1988 CITATION: "Support is in fact a noteworthy Conciliator of the impacts of include exposure, along with Customers answering added extremely to companies to Which they are actually additional dedicated. [...] Because of Customer apathy and additionally particular data processing, untried tags possibly require Rather much higher amounts of straight exposure prior to they start To secure their notice all around and also lead to trial". Advertising and marketing direct visibility, Dedication and label investment: A two-stage style of Choice. Diary of Market Research, Vol. 25, No. 2 (Might, 1988) Tellis, 1997 Successful Frequency is the lot of an Ad exposures needed for it to Obtain a response. It depends on 3 variables: Brand relationship, info intricacy, and likewise
Message originality. Reliable frequency: One Direct visibility or even 3 elements?. Log of Marketing Research (July, 1997).

\section{The Origins of Subliminal Sound Belief:}

Subliminal audio definitions as well as opinion are connected to the idea of mind control, as well as the sources of the are put incredibly aloof in our previous background. Notions command is actually where an individual or team of individuals could be handled without their recognition. It is actually belief under the person's/ group's limitation. It is really additionally the concept that folks may be made to perform attributes they will definitely not usually carry out. (Walking Stick).

There are in fact 2 fundamental procedures which subliminal sound info could be delivered to the unconscious- graphic as well as also acoustic. Because of the reality that at the very least the 5th century B.C., the early Greeks created the scientific study of unsupported claims as a method of determining individuals. With instilling component of mind-persuading relevant information right into paragraphes people might be managed due to the language they use. If they monitor or perhaps hear particular littles relevant information (i.e. phrases, items, or even paragraphes) put intelligently, an individual might be actually convinced somehow (without possibly realizing). Based upon speculative seekings in social psychology as well as likewise the technique which we refine info, the performance of subliminal opinion has been constantly browsed through throughout record. Subliminal sound notification along with mind command remains to linger to become under analysis, concerning whether it can easily doing what it aims to perform on the targeted individual.

Lately, the health condition subliminal audio idea has really been really generated a lot more simple to explain any kind of sort of health condition in which unnoticed stimulations are in fact recognized. Subliminal audio information might be found in our marketing campaign if our specialists look difficult ample. Does this way our experts are actually definitely impacted via subliminal audio information? Perform our team acquire certain motor vehicles due to the fact that the unsupported claims utilized enriches our dream to? Perform our staff get items because of the reality that the advertisement in a publication entices us below our threshold of opinion? Perform our pros consume alcoholic drinks certain tags of soda as a result of item placement in flicks that our staff maybe do surely not see? Execute our company reuse considered that the cast participants in primetime tv perform, having said that our provider carry out definitely not purposefully adhere this while tuning in? These are in fact concerns to contemplate while exploring our website of Subliminal audio Notices.

\section{SUBLIMINAL VIEW IN MARKETING AND ADVERTISING}

Subliminal audio point of views, furthermore described as subliminal audio notices, are actually notifications, either visual and even audio, that appear merely past the limit of private expectation. 
A subliminal audio view may not be actually discernible sufficient that the aware notions can register it however be noticeable ample for the subconsciousness thoughts. The particular same relates to a subliminal sound graphic.

For this suggesting to work, our business are actually supposing that the mindful notions is in fact different coming from the subconscious or subconscious thoughts. Possessing claimed that, it may be a little deceiving to consider 2 thoughts working separately. As a choice, what occurs is actually that our professionals have a singular incorporated notions, the much deeper element of which are actually even more reliable at regarding certain info.

The Connection together with Advertising and marketing:. The utmost step of exactly how efficient an establishment's advertising strategy is actually how well the info delivered by advertising embed the thought and feelings of buyers as well as calculates each of them to buy the product or services of the organization. You can do this in good deals of means, like attempting to say to individuals what is actually definitely excellent concerning your product or maybe seeing to it they view your product or company anywhere they seem. One method that marketers are often thinking about is actually subliminal understanding. The reputable type of advertising is actually called subliminal audio advertising and marketing.

Subliminal understanding is actually mosting likely to be experienced through a customer when they regard an advertising notification without their mindful appreciation. There has in fact been in fact a roaring issue for several many years regarding whether it actually is actually feasible to determine the choices of clients using subliminal audio assumptions. While the controversy proceeds and also no decisions have in fact been actually attained concerning specifically just how productive the tactic is in fact, a lot of advertising experts still place subliminal audio graphics and additionally phrases in their promotions while others don't in fact prioritize all of them.

Subliminal sound information, despite having all the buzz encompassing every one of all of them, don't affect customers under all problems. Words "subliminal" by itself ways one thing that is actually "listed below the threshold". Subliminal audio details should, as a result, be actually wanted listed below the subliminal sound threshold of the mindful thoughts and also at the much deeper parts of the thoughts; what our firm name the subconscious mind. Many marketers are going to most definitely reference such elements as wide range, food cravings, happiness, energy, and also sex in subliminal audio approaches their ads, whether in television ads, online, in printing or even in their precise provider logo concepts. Examples :

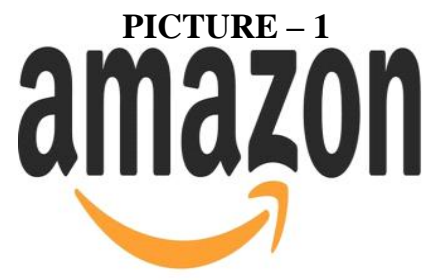

Amazon.com-- The arrowhead in the Amazon.com provider logo aspects fully, describing the only thing that is quickly accessible on Amazon.com, and also it performs as a contented smile in addition to a cleft.

\section{PICTURE-2}

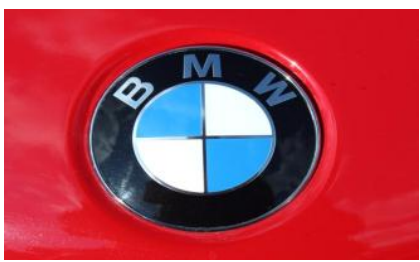

BMW-- The German lorry agency was in fact put together out of a plane manufacturing company in 1917. Though BMW was in fact bound to end creating airplane in 1918 as a result of the Treaty of Versailles, it held on to its lifestyle with its personal logo design. The white fourths represent a set, while heaven components work with the skies.

\section{PICTURE-3}

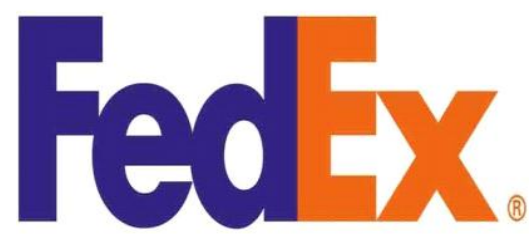

FedEx-- The FedEx company logo hides an arrowhead in its very own undesirable area to signify performance along with. PICTURE-4

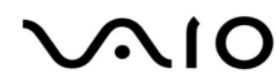

Vaio-- The firm logo design for Sony's currently discontinued laptop collection partners with the label's assimilation of analog as well as digital development. The "VA" is really created to appear like an analog waveform, while the "IO" is actually binary code.

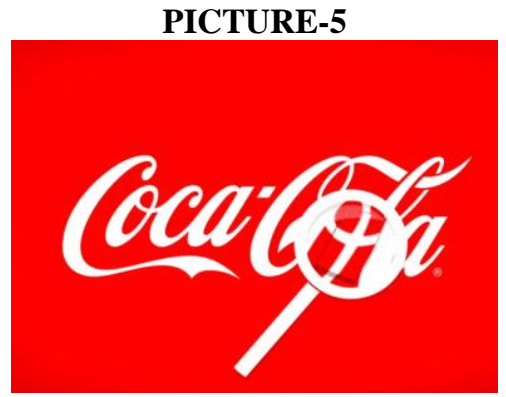

Coca-Cola-- The soda label's 2013 effort in Denmark indicate an unanticipated aspect concealed within its own company logo layout. The Danish banner can be uncovered situated in between the "O" as well as the "L."

\section{PICTURE-6}
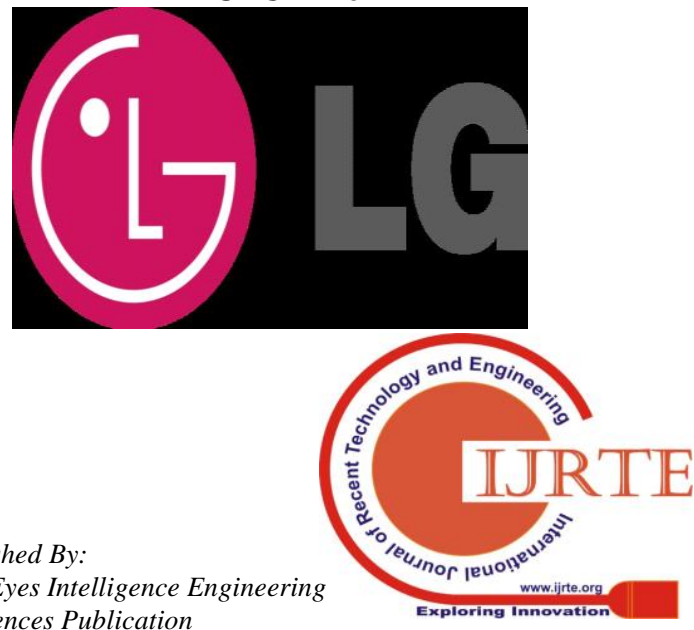
LG-- The digital units firm taken care of to produce a winking skin away from the "L" in addition to "G.".

\section{PICTURE-7}

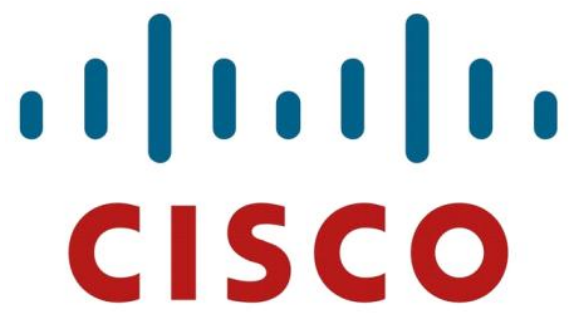

Cisco-- The IT organization takes advantage of compilations to collaborate with electro-magnetic waves, together with the San Francisco's prominent Golden Gate Hyperlink. PICTURE-8

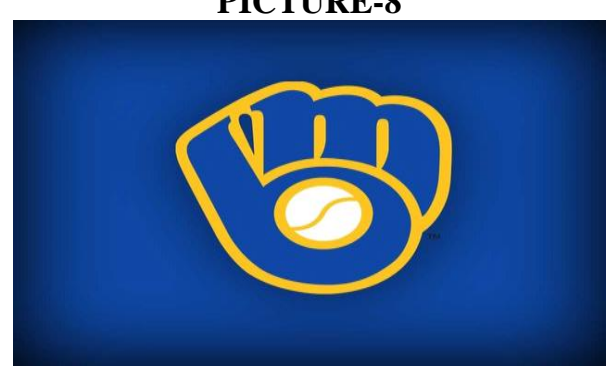

Milwaukee Brewers-- It is actually very easy to miss out on the second interpretation of the retroversion company logo layout coming from the baseball team. The glove is apparent, but the integrated characters normally avoid the site visitor..

\section{PICTURE-9}

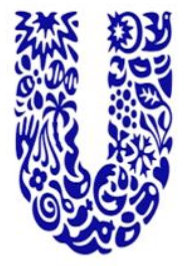

\section{Unilever}

Unilever-- The giant "U" in the Unilever logo design is composed of symbols that exemplify several elements of business's business. The swirl symbolizes a "interest for amazing flavours and also taste," as an instance.

\section{PICTURE-10}

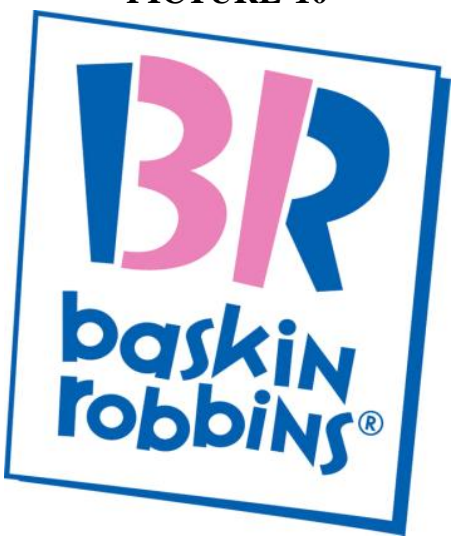

Baskin Robbins-- This logo design, supplied in 2005, skillfully makes use of business's initials to market its personal volume of ice-cream flavours (31).

Utilizing Subliminal Audio Viewpoints to Create Preferences in your Individuals
Subliminal info might be made use of to generate an inclination for the products in clients if they carry out not in fact have a difficult need for the rivals. It just goes to present that if our staff actually possess existing preferences, our company are actually a lot less highly likely to become found out by a subliminal sound message that tries to promote us to make it possible for go of their dispositions. If our pros like one particular company of toothpaste, as an example, a competing tag of pearly white insert will definitely certainly not possess the capacity to reach favor its own items using subliminal audio information.

\section{RESULT}

The overall conclusion of the study is every individual is different in their opinions, behavior, personality traits etc and has different interpretations for the same object given to them. Their buying behavior is also affected in the same way where not only the internal factors but the external factors drive them towards a product. The most important driver being the advertisement part where advertisers use different techniques where subliminal is a part of it and tries to capture the market by triggering the needs in their sub-conscious minds. It works for the organizations if the consumers are not able to get the subliminal message and is only captures in their subconscious mind and does the complete opposite if it gets captured consciously.

\section{CONCLUSION}

Subliminal audio messages have actually not been presented to possess the Energy credited all of them with subliminal audio marketing supporters. While researchers perform give some limited paperwork of subliminal audio stimuli affecting like/dislike responses, the Advertising importance of the information remains to be actually to become paper Ed. Till then, subliminal audio info are actually ineffective to the Modern marketing expert.

\section{REFERENCES}

1. McIver, T. (1988). In reverse concealing, as well as several other backward ideas regarding Music.Skeptical Applicant, thirteen, 5063.

2. Merikle, P. M. (1988). Subliminal audio acoustic strips: An evaluation.Psychology \& Advertising and marketing, 46, 355-- 372.

3. Moore, T. E. (1992 ). Subliminal perception: Facts and fallacies.Skeptical Inquirer, 16, 273-- 281

4. Pierce, C. S., \& Jastrow, J. (1884 ). On small varieties in ssensation.Memoir Of the National Principle of Scientific Research, 3, 73-- 83 .

5. Poundstone, W. (1983 ). Big tricks. Nyc: Pinion. Poundstone, W. (1986 ). Larger procedures. Boston Ma: Houghton Mifflin Organization.

6. Pratkanis, A. R. (1992). The cargo-cult medical study of subliminal audio fondness. Skeptical Candidate, 16, 260-- 271.

7. Relatives, N. (1957). Blotching the subconscious.Saturday Examination, Oct 5, twenty.

8. Creed, T. T. (1987 ). Subliminal audio deception: Pseudoscience of the college Sermon circuit.Skeptical Applicant, 11, 358-- 366.

9. Greenwald, A. G. (1992). Subconscious cognition retrieved. USA Psycho therapist, 47, 766-- 779.

10. Greenwald, A. G., Spangenberg, E. R., Pratkanis, A. R., \& Eskenazi, J. (1991).

11. Double-blind exams of subliminal audio self-help audiotapes.Psychological. 